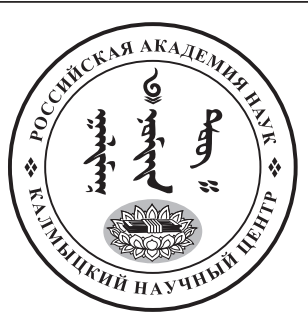

Published in the Russian Federation

Oriental Studies (Previous Name: Bulletin of the Kalmyk Institute

for Humanities of the Russian Academy of Sciences)

Has been issued as a journal since 2008

ISSN: 2619-0990; E-ISSN: 2619-1008

Vol. 14, Is. 3, pp. 515-530, 2021

Journal homepage: https://kigiran.elpub.ru

УДК / UDC 902/904

DOI: 10.22162/2619-0990-2021-55-3-515-530

\title{
Результаты работ на грунтовом могильнике Максимовка I в лесостепном Поволжье в 2018 г.
}

\author{
Аркадий Иванович Королев ${ }^{1}$ Владимир Николаевич Мышкин ${ }^{2}$, \\ Антон Александрович Шалапинин ${ }^{3}$ \\ 1 Самарский государственный социально-педагогический университет (д. 65/67, ул. М. Горького, \\ 443099 Самара, Российская Федерация) \\ кандидат исторических наук, доцент, декан исторического факультета \\ iD 0000-0001-8452-4386. E-mail: arkorolev@gmail.com
}

${ }^{2}$ Самарский государственный социально-педагогический университет (д. 65/67, ул. М. Горького, 443099 Самара, Российская Федерация)

кандидат исторических наук, заведующий археологической лабораторией

iD 0000-0003-3489-6776. E-mail: vnm59@bk.ru

${ }^{3}$ Самарский государственный социально-педагогический университет (д. 65/67, ул. М. Горького, 443099 Самара, Российская Федерация)

кандидат исторических наук, научный сотрудник научно-исследовательской части

iD 0000-0001-9434-7811. E-mail: anton-shalapinin@ro.ru

(C) КалмНЦ РАН, 2021

(C) Королев А. И., Мышкин В. Н., Шалапинин А. А., 2021

Аннотация. Введение. Данная статья посвящена результатам раскопок на грунтовом могильнике Максимовка I, расположенном в лесостепном Поволжье. Данный памятник является уникальным, поскольку содержит погребальные комплексы различных эпох. Целью работы является введение в научный оборот материалов из раскопок 2018 г. на указанном памятнике. В задачи исследования входят описание и характеристика исследованных археологических комплексов, определение их культурно-хронологической принадлежности. Материаль. Культурный слой памятника был слабо насыщен и содержал керамику эпох неолита, энеолита и бронзы, а также орудия из камня и отходы камнеобработки. На памятнике изучено три погребения. Костяк первого погребения располагался вытянуто на спине с ориентировкой головы на север-северо-восток. Инвентарь включал предметы из железа (фрагмент котла, удила, стержневидные предметы, кресало), точильное и кресальные камни. Положение погребенного следующего захоронения сидячее: кости ног согнуты в коленных суставах. Голова погребенного направлена на северо-восток. Инвентарь захоронения содержал кольцо из цветного металла, 
костяную подвеску, кремневую пластину, трубчатые пронизки. Третье погребение также сидячее и ориентировано головой на северо-восток. Захоронение безынвентарное. Также на памятнике частично изучено два сооружения. Результатыл. Первое погребение относится к золотоордынскому периоду эпохи средневековья (датируется второй половиной XIII-XIV вв. н. э.). Второе захоронение имеет ряд общих черт с погребальными комплексами среднего и позднего энеолита лесостепного Поволжья. Культурно-хронологическая атрибуция третьего захоронения не определена в связи с нестандартным положением костяка и отсутствием инвентаря.

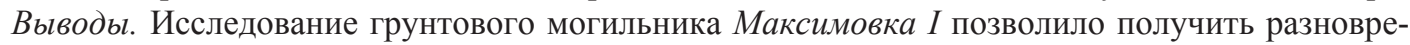
менные материалы, включающие комплексы неолита, энеолита, эпохи бронзы, средневековье. Ключевые слова: неолит, энеолит, эпоха бронзы, средневековье, золотоордынский период, погребальный обряд, грунтовый могильник, лесостепное Поволжье

Благодарность. Исследование выполнено по проекту Российского научного фонда № 19-7810001 «Этно-культурное взаимодействие населения Среднего Поволжья в каменном веке (мезолит-энеолит)».

Для цитирования: Королев А. И., Мышкин В. Н., Шалапинин А. А. Результаты работ на грунтовом могильнике Максимовка I в лесостепном Поволжье в 2018 г. // Oriental Studies. 2021.

T. 14. № 3. С. 515-530. DOI: 10.22162/2619-0990-2021-55-3-515-530

\title{
Results of the 2018 Archaeological Investigation at the Burial Ground of Maksimovka I in the Forest-steppe Volga Region
}

\author{
Arkady I. Korolev', Vladimir N. Myshkin², Anton A. Shalapinin ${ }^{3}$ \\ ${ }^{1}$ Samara State University of Social Sciences and Education (65/67 Gorky St., 443099 Samara, Russian \\ Federation) \\ Cand. Sc. (History), Associate Professor, Dean of the Faculty of History \\ iD 0000-0001-8452-4386. E-mail: arkorolev@gmail.com
}

${ }^{2}$ Samara State University of Social Sciences and Education (65/67 Gorky St., 443099 Samara, Russian Federation)

Cand. Sc. (History), Head of the Archaeological Laboratory

iD 0000-0003-3489-6776. E-mail: vnm59@bk.ru

${ }^{3}$ Samara State University of Social Sciences and Education (65/67 Gorky St., 443099 Samara, Russian Federation)

Cand. Sc. (History), Researcher of the Research Unit

iD 0000-0001-9434-7811. E-mail: anton-shalapinin@ro.ru

\author{
(C) KalmSC RAS, 2021 \\ (C) Korolev A. I., Myshkin V. N., Shalapinin A. A., 2021
}

\begin{abstract}
Introduction. This is a report on the results of archaeological excavations at Maksimovka I, the subterranean burial ground located in the forest-steppe Volga region. The site is unique because it contains burial complexes of different epochs. The purpose of the paper is to introduce the materials found during the 2018 excavations for the attention of the academic community. In particular, the paper focuses on the description and characterization of the archaeological complexes under investigation, and, also, on their cultural-chronological attribution. Data. The cultural layer was not particularly rich but contained fragments of Neolithic, Eneolithic, and Bronze Age ceramics, stone tools, and waste left after stone processing. Three burials were examined in the excavation area. The first burial comprised the skeleton of a deceased person in a supine position; the head oriented to the northnortheast; the grave goods included iron items (a fragment of a boiler and of a bit, rod-shaped items, and a firesteel), grindstones, and flints. The second buried person was found in the seated position, leg bones bent at the knee joint, head oriented to northeast; the finds included a nonferrous metal ring, a bone pendant, a silicon wafer, and tubular beads. The third buried person was also in a seated
\end{abstract}


position, head oriented to the northeast; no grave goods were found in the third burial. Also, two other burial constructions recovered on the site were partially examined. Results. The first burial was attributed to the Golden Horde period in the Middle Ages (the second half of the $13^{\text {th }}$ or the $14^{\text {th }} \mathrm{c}$.). The second burial has a number of parallels to burial complexes of mid-late Eneolithic era of the forest-steppe Volga region. The third burial was left unidentified in terms of its cultural-chronological attribution, granted the non-standard position of the skeletal remains in the grave and the absence of goods. Conclusions. The examination of the subterranean burial ground Maksimovka I has allowed to introduce the archaeological material of different periods, such as Neolithic, Eneolithic, Bronze, and Middle Ages.

Keywords: Neolithic, Eneolithic, Bronze Age, Middle Ages, Golden Horde period, burial rite, ground burial ground, forest-steppe Volga region

Acknowledgements. The reported study was funded by the Russian Science Foundation - project name 'Ethno-cultural interaction of the population of the Middle Volga region in the Stone Age (Mesolithic-Eneolithic)' (state reg. no. 19-78-10001).

For citation: Korolev A. I., Myshkin V. N., Shalapinin A. A. Results of the 2018 Archaeological Investigation at the Burial Ground of Maksimovka I in the Forest-steppe Volga Region. Oriental Studies. 2021. Vol. 14 (3): 515-530. (In Russ.). DOI: 10.22162/2619-0990-2021-55-3-515-530

\section{ङ}

\section{Введение}

Первостепенное значение для изучения древней истории населения Волго-Уральского региона является введение в научный оборот новых материалов из раскопок. Грунтовый могильник Максимовка I, расположенный на берегу р. Самара в лесостепном Поволжье, представляет особый интерес в связи с тем, что на данном памятнике выявлены погребальные комплексы эпохи энеолита и средневековья. Данные материалы ввиду грунтового характера захоронений являются достаточно редкими для данного региона. Результаты исследования первого года работ на могильнике Максимовка I опубликованы [Цибин, Шалапинин 2019: 6-16]. Целью данной работы является публикация результатов раскопок 2018 г.

\section{Материалы}

Грунтовый могильник располагается на северо-западной окраине с. Максимовка муниципального района Богатовский Самарской области в 480 м к востоку-северо-востоку от места современного впадения р. Съезжая в р. Самара (рис. 1). Памятник выявлен в 2017 г. В. А. Цибиным во время проведения разведочных работ. Для данного памятника им была определена территория, и в шурфе № 1 изучено погребение эпохи энеолита [Цибин, Шалапинин 2018: 16; Цибин, Шалапинин 2019: 8-11]. В 2018 г. на могильнике к востоку от шурфа
№ 1 был заложен раскоп общей площадью

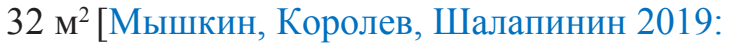
15] (рис. 2: 2).

Стратиграфия раскопа следующая (рис. 2: 1):

1) дерн, мощностью до 5 см. Данный слой фиксируется по площади раскопа, за исключением участка под дорогой;

2) переотложенный слой, который формировался в ходе хозяйственной деятельности на территории памятника (строительство и функционирование маслозавода и проселочной дороги). Данный слой состоит из темно-серого и серо-коричневого песка, перемешанного с бытовым мусором, кирпичом, галькой, древесной трухой, щебнем. Мощность слоя от 10 до 100 см на разных участках памятника;

3) слой темно-серого песка. Данный слой фиксировался в восточной части раскопа. Мощность данного слоя составляет от 3 до $38 \mathrm{cm;}$

4) слой серого песка, постепенно высветляющийся к низу. Мощность данного слоя до $60 \mathrm{cm;}$

5) светлый серо-коричневый песок (предматерик). Мощность данного слоя до $18 \mathrm{~cm}$;

6) материк - коричневый песок, фиксируется с глубины -36 см от условного «0».

Культурный слой слабо насыщен археологическим материалом и включал фраг- 
менты керамики эпох неолита (2 экз.), энеолита (1 экз.) и эпохи бронзы (20 экз.), а также орудия из камня (5 экз.) и отходы камнеобработки (13 отщепов, 2 скола, 3 осколка, 1 кусок кремня, 1 чешуйка).

Среди находок, полученных при разборке слоя, следует отметить несколько предметов.

Среди кремневых предметов выделим скребок на отщепе прямоугольной формы с тремя рабочими краями и жальцем из серо-коричневого кремня (рис. 3: 6); концевой скребок на отщепе из белого кремня (рис. 3: 7); проколку на отщепе полупрозрачного серого кремня (рис. 3: 8); медиальную часть пластины с ретушью из кремня желтого цвета (рис: 3: 9); обломок наконечника стрелы из кремня серого цвета (рис. 3: 10).

Найденный в культурном слое орнаментированный фрагмент стенки сосуда эпохи неолита имеет серо-коричневый цвет и толщину 0,9 см. Орнамент состоит из аморфных ямок и оттисков короткого гребенчатого штампа (рис. 3: 3).

В число фрагментов глиняных сосудов эпохи бронзы, представленных, главным образом, неорнаментированными стенками, входят фрагменты двух отогнутых наружу венчиков. Их цвет коричневый, в изломе черный. Тесто плотное, с примесью шамота. Один венчик имеет орнамент из поясков овальных и округлых ямок (рис. 3: 1), второй украшен пояском округлых ямок (рис. 3: 2).

Среди них неорнаментированное плоское днище со следами выщелоченной раковины на поверхности (рис. 3: 5).

В пределах раскопа исследовано три погребения (рис. 3: 2).

Погребение № 2 (рис. 4) находилось в юго-восточной части раскопа ${ }^{1}$. Могильная яма вытянутых очертаний с небольшим расширением в северной части и округлыми углами (кроме северо-восточного) была ориентирована длинной осью по линии север-северо-восток - юг-юго-запад. Размеры ямы: максимальная длина - 2,15 м, максимальная ширина - 0,9 м. Могильная яма фиксировалась с уровня +27-30 см от условного «0». Глубина могильной ямы от уровня первой фиксации до дна составляет 90-97 см, от условного «0»-63-67 см. За-

\footnotetext{
${ }^{1}$ Погребение № 1 было исследовано в 2017 г.
}

полнение - темный серо-коричневый песок с вкраплениями коричневого, светло-коричневого, светло-серого песка, угольков размерами до 2 см.

В заполнении ямы были обнаружены несколько предметов. На глубине 30 см от условного «0» найдено звено составных железных удил, изготовленное из прямоугольного в сечении стержня. Один конец стержня представляет собой неподвижное кольцо, в которое вставлено кольцо, имевшее диаметр 2,8 см и являвшееся подвижным. Это кольцо изготовлено из треугольного в сечении прута. Противоположный конец стержня загнут в петлю. Размеры предмета $-10,7 \times 3,4 \times 1,1-2,3$ см (рис. 5: 5).

На глубине -48 см от условного «0» находился стержневидный железный предмет, изготовленный из овального в сечении прута и имевший размеры $3,6 \times 0,7 \times 0,5$ см (рис. 5:4).

Кроме того, при выборке заполнения ямы найдены неорнаментированный фрагмент керамики размерами $1,5 \times 2$ см и кремневый отщеп.

На дне ямы лежал скелет взрослого мужчины, умершего в возрасте 40-50 лет. ${ }^{2}$ Костяк располагался вытянуто на спине головой на север-северо-восток. Череп лицевой частью повернут на восток. Плечевая кость правой руки располагалась вдоль грудной клетки. Локтевая и лучевая кости, а также кисть правой руки находились на костях таза. Левая рука была согнута в локтевом суставе, ее предплечье и кисть располагались в районе пояса умершего.

Около левого плеча и верхней челюсти погребенного на дне могилы лежал железный предмет подквадратных очертаний, вероятно, фрагмент верхней части котла, распавшегося на 3 части. Один край котла утолщен на внутренней стороне и слегка закруглен в профиле. На вогнутой стороне сохранились кусочки древесины (коры?). Размеры фрагмента - 9,5×8,7 см (рис. 5: 1). Рядом находился еще один железный предмет с одним узким и вторым уплощенным и более широким концом. На узком конце сохранились частички древесины (рис. 5: 3). Под скелетом в районе пояса располагалось железное кресало, имеющее калачевидную

${ }^{2}$ Все определения пола и возраста погребенных выполнены антропологом А. А. Хохловым. 
форму, треугольный выступ и несомкнутые концы (рис. 5: 2), три кресальных камня аморфной формы, изготовленных из кремня коричневого цвета и имеющих следы ударов на поверхности (рис. 5: 6, 7, 9), а также точильный камень подпрямоугольной формы (рис. 5: 8). На костях погребенного и под ними были зафиксированы следы коры или древесной трухи до 1,6 см толщиной. Скелет частично перекрывала кора. Она обнаружена и под скелетом. Пятно древесной коры имело подпрямоугольную форму. Его размеры 75×170 см. Структура коры местами хорошо сохранилась в области стоп. Она двухслойная; первый слой ярко-лилового оттенка, второй - черный, в области стоп кора, возможно, была обуглена. Толщина коры составляла 1-1,6 см. По сторонам тазовых костей скелета сохранились загнутые вверх участки коры.

Погребение № 3 (рис. 6) располагалось в северной части раскопа. Контуры могильной ямы не фиксировались. Ребенок, умерший в возрасте 6-7 лет, был захоронен сидя. Череп располагался над костями грудного отдела и над тазовыми костями. В момент расчистки череп был направлен теменной частью в северо-восточном направлении. Согнутые в коленях ноги завалились в западном направлении. Отдельные позвонки находились к северу и юго-востоку от черепа. Костяк посыпан охрой. Около костей ног на глубине -31 см от условного «0» находились две пронизки из трубчатых костей мелкого животного. На их торцевых сторонах прослеживаются следы обрезки и прошлифовки. Первая пронизка имеет длину $1,3 \mathrm{~cm}$, максимальный диаметр $0,5 \mathrm{~cm}$, вторая - длину 1,2 см, диаметр - 0,6 см (рис. 7: 3, 4).

К юго-западу от костяка располагались коленная чашечка, покрытая охрой, и на глубине -28 см от условного «0» - кремневая пластина с ретушью по двум граням из кремня серо-коричневого цвета с белой коркой (рис. 7: 2). Её длина - 4,3 см, максимальная ширина $-1,8$ см, толщина 0,1 см. Пластина покрыта охрой. При разборе погребения под черепом на глубине -30 см от условного «0» была обнаружена плоская костяная подвеска вытянутой в плане формы. Края подвески зубчатые. В верхней части предмета имеется сквозное отверстие диаметром 0,4 см. Длина подвески -
4,9 см, максимальная ширина $-2,9$ см, толщина - 0,2 см (рис. 7: 1). В норе под костяком (на глубине -41 см от условного «0») находилось кольцо из цветного металла (меди?) с приостренными несомкнутыми концами, один из которых расслоился. Кольцо изготовлено из прутка, имеющего подчетырехугольное с закругленными углами поперечное сечение и толщину $0,2 \mathrm{~cm}$. На прутке имеется участок с браком отливки, который частично выправили проковкой. Диаметр кольца - 2,6-2,7 см (рис. 7: $5)$.

Погребение № 3 по ориентировке и положению скелета, инвентарю, наличию посыпки охрой аналогично погребению № 1 этого же могильника, изученному в 2017 г. и отнесенному к эпохе энеолита.

Погребение № 4 и сооружение № 1 (рис. 8: 1) находились в восточной части раскопа.

Погребение № 4 (рис. 8: 1). На уровне поверхности материка удалось зафиксировать границы могильной ямы в ее северной, западной и южной частях. Границы восточной части могильной ямы на этом уровне точно определить не удалось, из-за сходства заполнений погребения № 4 и сооружения № 1. Заполнение могильной ямы цветом и структурой грунта не выделялось на фоне заполнения сооружения № 1. На глубине -65 см и -69 см от «0» по материку была зафиксирована западная граница могильной ямы и, частично, северная и южная. Могильная яма погребения № 4 в восточной части соединялась с сооружением № 1 , и четкой границы между ними не было. Восточный край могильной ямы был предположительно определен по северной стенке и, отчасти, по южной на глубине -90 от «0», а также при зачистке дна могильной ямы после изъятия костяка на глубине $-122-124$ см от «0» по остаткам заполнения серого песка, когда заполнение сооружения № 1 было выбрано уже до материка. Могильная яма имела в плане вытянутую подовальную форму и была ориентирована длинной осью по линии север-северо-восток - юг-юго-запад. Размеры ямы на уровне фиксации (-6569 см от 0): длина - 1,25 м, ширина составляла, вероятно, около 0,7 м. В верхней части могила имела слегка наклонные стенки, а у северной короткой стенки пологий уступ шириной 0,14 м. Начиная с глубины около 
-85 см, стенки ямы становились отвесными. Таким образом, по направлению ко дну могила уменьшалась в размерах. Ее размеры у дна: длина $-0,98$ м, ширина - около 0,6 м. Дно ямы зафиксировано на глубине -124 см от «0». Заполнение представляло собой однородный песок серого, ближе ко дну светло-серого цвета.

Захоронение № 4 принадлежало женщине, умершей в возрасте 40-55 лет. Погребенная располагалась в позе сидя, завалившись вправо, опираясь правым плечом и поднятым вверх коленом правой ноги о западную стенку ямы, а правой височной частью черепа - о северную стенку. Кости скелета сохранили анатомическое положение в сочленениях. Череп лежал глазницами вверх и теменной частью на северо-восток. Нижняя челюсть занимала анатомическое положение. Шейные позвонки были изогнуты и соответствовали запрокинутому назад черепу. Расположение ключиц, лопаток, ребер, позвонков соответствовало анатомически положению тела в позе сидя с завалом в правую сторону. Кости согнутой в локте правой руки опирались локтевым суставом о дно ямы, эпифизом плечевой кости и кистью - о западную стенку. Кости кисти были направлены вверх, около коленного сустава правой ноги. Кости левой руки были также согнуты в локте и кистью лежали на тазобедренном суставе. Кости ног погребенной были сильно согнуты в коленных суставах. Колено правой ноги было направлено вверх и опиралось о западную стенку ямы, кости стопы упирались в кости левой ноги около коленного сустава. Кости левой ноги лежали практически горизонтально на дне могильной ямы, а кости стопы частично находились под тазовыми костями. Такое положение костей стопы, находившейся в анатомическом порядке, показывает, что такое положение левой ноге было придано специально. Тазовые кости находились на дне могильной ямы в положении сидя с легким завалом к северо-западу на глубине $-122-124$ см от «0».

Таким образом, судя по расположению костей, погребенная была захоронена в положении сидя с согнутой коленом вверх правой ногой, согнутой в колене и поджатой назад под таз стопой левой ногой. Руки были согнуты в локтях, кисть правой руки лежала на колене правой ноги, кисть ле- вой руки, видимо, лежала в области паха. Кости скелета сохранили практически ненарушенное положение, в том числе после естественного разложения мягких тканей погребенной. Это свидетельствует о том, что яма имела небольшие размеры, которые не позволили распасться скелету в процессе археологизации погребения.

В заполнении могильной ямы на глубине -103 см от «0», в 14 см к востоку от левой лопатки скелета была найдена заготовка наконечника из серо-розового кремня (рис. 8: 2). Длина изделия -5 см, ширина $-2,6$ см, толщина -1 см. Заготовка имеет двустороннюю обработку крупной ретушью.

Сооружение № 1 зафиксировано на глубине -65-69 см (рис. 8: 1). На этом уровне пятно заполнения этого сооружения сливалось с пятном погребения № 4 или перекрывало его. Заполнение представляло собой песок серого цвета, с пятнами темно-серого и коричневого оттенков от нор землеройных животных. Выборка заполнения сооружения № 1 показала, что определение его западного края осложнено наличием погребения № 4. Судя по стенкам, которые были определены после расчистки сооружения № 1, его часть, выявленная в квадратах 2 и 4, имела, скорее всего, полукруглую в плане форму. В пределах изученной площади максимальная ширина данного сооружения по линии север-юг (по верхнему уровню фиксации в профиле восточной стенки) составляла 2,66 м. Размеры выступающей части по линии восток-запад составили 31-33 см. Сооружение имело пологие стенки и слегка округлое дно.

Сооружение № 2 зафиксировано в юго-западной части раскопа (рис. 2: 1). В квадрате 4 раскопа располагалась лишь северная часть сооружения. Сооружение выступало из стенки раскопа на 0,2 м, поэтому форма его не установлена. Можно отметить, что граница пятна сооружения достаточно ровная, она ориентирована по линии запад-восток. В пределах изученной площади сооружение имеет округлые углы, а его максимальная ширина составляла в пределах 1,5 м. Оно имело пологие стенки и прорезало материк на незначительную глубину, равную 14 см. Основу заполнения данного сооружения составил серый песок. Ее глубина от уровня составляла 27 см от 
уровня поверхности предматерика (-2024 см от «0»). Вещи, антропологические или остеологические материалы в заполнении данного сооружения не обнаружены.

\section{Анализ полученных материалов}

Среди погребальных комплексов наиболее ранним является погребение № 3 (рис. 6). Это захоронение по ряду особенностей погребального обряда и облику вещей имеет целый ряд аналогий в материалах хвалынской энеолитической культуры, представленных в I и II Хвалынских могильниках, а также Хлопоковском могильнике. В погребениях указанных могильников также присутствует ориентировка погребенных головой на северо-восток, положение костяка с согнутыми ногами, посыпка покойного охрой, инвентарь из орудий на пластинах, пронизки и медные кольца [Агапов, Васильев, Пестрикова 1990: 121-127; Агапов 2010: 272; Васильев, Овчинникова 2000: 259; Васильев 2003: 82-83; Малов 1982: 82 94; Малов 2008: 119-128; Моргунова 2011: 105, 108, 110; Рындина 2010: 235].

Погребение № 3 грунтового могильника Максимовка I имеет сходство с энеолитическими захоронениями Мурзихинского могильника в Прикамье, где также зафиксирована традиция захоронения умерших в сидячем положении с полусогнутыми ногами и обычай посыпания погребенных охрой. Следует отметить сходство некоторых предметов погребального инвентаря двух рассматриваемых могильников. В частности, в захоронении № 102 Мурзихинского могильника обнаружен фрагмент костяной подвески с зубчиками по краям [Чижевский 2008: 367-371], сходной с подвеской из могильника Максимовка I. Отмеченные аналогии позволяют предварительно датировать погребение № 3, раскопанное в 2018 г., средним или поздним энеолитом. В калиброванном значении указанный диапазон определяется между 5250-3500 ВС [Королев 2020: 44-45; Кузнецов 2020: 48; Сомов, Шалапинин 2019: 237].

Погребение № 2 грунтового могильника Максимовка I, судя по особенностям обряда (положение погребенного вытянуто на спине и его северо-северо-восточная ориентировка), а также погребальному инвентарю (кольчатые удила, калачевидное кресало), является захоронением кочевника и совер- шено в эпоху средневековья. Оно имеет ряд общих черт с другими грунтовыми захоронениями указанной эпохи, открытыми в бассейне р. Самары. На Старо-Елшанском могильнике в могильных ямах зафиксированы остатки дерева и кусочки древесного угля. На Виловатовском и Максимовском могильниках обнаружены кресала и кресальные камни. Удила, аналогичные максимовским, найдены при исследовании Александровского и Новопавловского курганных могильников в лесостепном Заволжье, в захоронениях золотоордынского периода, датированных второй половиной XIII-XIV вв. н. э. [Васильева 1979: 220-230; Васильева 2000: 340-342].

Культурная принадлежность погребения № 4 не определена. На дне погребения или непосредственно на скелете вещи не найдены, а кремневый предмет, обнаруженный в заполнении ямы, видимо, отношения к погребению не имеет. Можно лишь предположить, что поскольку верхний уровень фиксации могильной ямы № 4 располагался ниже верхнего уровня фиксации могильной ямы погребения № 2, то рассматриваемое захоронение может быть датировано более ранним временем, чем средневековый период. Сохранность костей значительно лучше, чем у погребений энеолитической эпохи. Сидячее положение костяка отличается от сидячего или полусидячего положения скелета из погребения № 3, что ставит под сомнение возможность отнесения его к энеолиту.

Относительно хронологической последовательности сооружения № 1 и погребения № 4 необходимо заметить, что признаки прорезания или нарушения могильной ямой пятна сооружения № 1 отсутствовали. На уровне фиксации (на уровне материка) сооружения и места погребения было отмечено одно пятно однородного заполнения. Вероятно, сооружение № 1 имеет более поздний характер по отношению к погребению № 4. Оно могло частично перекрыть погребение, не нарушив при этом скелет.

\section{Выводы}

Исследование грунтового могильника Максимовка I позволило получить разновременные материалы. На памятнике отложились культурные напластования неолита, энеолита и эпохи бронзы. В результате работ 
2018 г. частично изучено два сооружения и исследовано три захоронения. Одно погребение датируется эпохой энеолита, второе

\section{Литература}

Агапов 2010 - Агапов Д. С. Медные изделия в погребальном обряде хвалынских энеолитических могильников // Хвалынские энеолитические могильники и хвалынская энеолитическая культура. Исследования материалов. Самара: СРОО ИЭКА «Поволжье», 2010. C. 258-283.

Агапов, Васильев, Пестрикова 1990 - Агапов С. А., Васильев И. Б., Пестрикова В. И. Хвалынский энеолитический могильник. Саратов: Изд-во Саратовского университета, 1990. $160 \mathrm{c}$.

Васильева 1979 - Васильева И. Н. Погребения кочевников на территории Куйбышевского Поволжья // Древняя история Поволжья. Куйбышев: Изд-во КГПИ, 1979. С. 202-240.

Васильева 2000 - Васильева И. Н. Золотоордынский период истории Самарского Поволжья // История Самарского Поволжья с древнейших времен до наших дней. Ранний железный век и средневековье. Самара: Издво СНЦ РАН, 2000. С. 293-346.

Васильев, Овчинникова $2000-$ - Васильев И. Б., Овчинникова Н. В. Энеолит // История Самарского Поволжья с древнейших времен до наших дней. Каменный век. Самара: Изд-во СНЦ РАН, 2000. С. 216-277.

Васильев 2003 - Васильев И. Б. Хвалынская энеолитическая культура Волго-Уральской степи и лесостепи (некоторые итоги исследования) // Вопросы археологии Поволжья. Вып. 3. Самара: Изд-во СНЦ РАН, 2003. C. 61-99.

Королев 2020 - Королев А. И. Поздний энеолит лесостепного Поволжья в свете радиоуглеродного датирования // Радиоуглерод в археологии и палеоэкологии: прошлое, настоящее, будущее. Мат-лы междунар. конф., посвящ. 80-летию старшего научного сотрудника ИИМК РАН, кандидата химических наук Ганны Ивановны Зайцевой. СПб.: ООО «Порто-принт», 2020. С. 44-45.

Кузнецов 2020 - Кузнецов П. Ф. Хронология хвалынской культуры Волго-Уралья // $\mathrm{Pa}$ диоуглерод в археологии и палеоэкологии: прошлое, настоящее, будущее. Мат-лы междунар. конф., посвящ. 80-летию старшего научного сотрудника ИИМК РАН, кандидата химических наук Ганны Ивановны Зай-
— второй половиной XIII-XIV вв. н. э., культурно-хронологическая принадлежность третьего захоронения не определена.

цевой. СПб.: ООО «Порто-принт», 2020. С. 47-50.

Малов 1982 - Малов Н. М. Хлопковский могильник и его место в энеолите Поволжья (по материалам раскопок 1977-1978 гг.) // Волго-Уральская степь и лесостепь в эпоху раннего металла. Куйбышев: Изд-во КГПИ, 1982. C. 82-94.

Малов 2008 - Малов Н. М. Хлопковский могильник и историография энеолита Нижнего Поволжья // Археология Восточно-Европейской степи. Вып. 6. Саратов: Научная книга, 2008. C. 32-134.

Моргунова 2011 - Моргунова Н. Л. Энеолит Волжско-Уральского междуречья. Оренбург: Изд-во ОГПУ, 2011. 220 с.

Мышкин, Королев, Шалапинин 2019 - Мышкин В. Н., Королев А. И., Шалапинин А. А. Раскопки грунтового могильника Максимовка I // Археологические открытия в Самарской области 2018 года. Самара: Изд-во СНЦ, 2019. С. 15.

Рындина 2010 - Рындина Н. В. Медные находки Хвалынского I могильника (итоги технологического исследования) // Хвалынские энеолитические могильники и хвалынская энеолитическая культура. Исследования материалов. Самара: СРОО ИЭКА «Поволжье», 2010. С. 234-257.

Сомов, Шалапинин 2019 - Сомов А. В., Шалапинин $A$. $A$. Соотношение неолитических и энеолитических комплексов лесостепного Поволжья по данным радиоуглеродного датирования // Самарский научный вестник. 2019. T. 8. № 2 (27). С. 229-239.

Цибин, Шалапинин 2018 - Цибин В. А., Шалапинин $A$. $A$. Разведочные работы у с. Максимовка в Богатовском районе // Археологические открытия в Самарской области в 2017 году. Самара: Изд-во СНЦ, 2018. С. 16. Цибин, Шалапинин 2019 - Цибин B.A., Шалапинин $A$. $A$. Погребение эпохи энеолита грунтового могильника Максимовка I из Самарского Заволжья // Вестник Волгоградского государственного университета. Серия 4. История. Регионоведение. Международные отношения. 2019. Т. 24. № 3. С. 6-16. Чижевский 2008 - Чижевский $A$. A. Погребения эпохи энеолита Мурзихинского II могильника // Труды II (XVIII) Всероссийского археологического съезда в Суздале. Т. І. М.: ИА РАН, 2008. С. 367-371. 


\section{References}

Agapov D. S. Copper goods in the burial rite of the Khvalynsk Eneolithic burial grounds. In: Khvalynsk Copper Age Cemeteries and Khvalynsk Copper Age Cultures. Results of Research. Samara: Povolzhye, 2010. Pp. 258-283. (In Russ.)

Agapov S. A., Vasilyev I. B., Pestrikova V. I. Khvalynsk Eneolithic Burial Ground. Saratov: Saratov State University, 1990. 160 p. (In Russ.)

Chizhevsky A. A. Eneolithic Burials of Murzikhinsky II burial ground. In: Proceedings of the $2^{\text {nd }}$ $\left(18^{\text {th }}\right)$ All-Russian Archaeological Congress in Suzdal. Vol. I. Moscow: Institute of Archaeology (RAS), 2008. Pp. 367-371. (In Russ.)

Korolev A. I. Late Eneolithic of the forest-steppe Volga region in the light of radiocarbon dating. In: Radiocarbon in Archaeology and Paleoecology: Past, Present, and Future. Jubilee conference proceedings. St. Petersburg: Porto-Print, 2020. Pp. 44-45. (In Russ.)

Kuznetsov P. F. Chronology of the Khvalynsk culture from the Volga-Ural region. In: Radiocarbon in Archaeology and Paleoecology: Past, Present, and Future. Jubilee conference proceedings. St. Petersburg: Porto-Print, 2020. Pp. 47-50. (In Russ.)

Malov N. M. Khlopkovsky burial ground and historiography of the Eneolithic Lower Volga region. In: Archaeology of the East European Steppe. Vol. 6. Saratov: Nauchnaya Kniga, 2008. Pp. 32-134. (In Russ.)

Malov N. M. Khlopkovsky burial ground and its place in the Eneolithic Volga region: summarizing excavations of 1977-1978. In: Volga-Ural Steppe and Forest-Steppe in the Early Metal Era. Kuibyshev: Kuibyshev State Pedagogical Institute, 1982. Pp. 82-94. (In Russ.)

Morgunova N. L. The Eneolithic Volga-Ural Interfluve. Orenburg: Orenburg State Pedagogical University, 2011. 220 p. (In Russ.)

Myshkin V. N., Korolev A. I., Shalapinin A. A. Excavation of Maksimovka I ground burial. In: 2018 Archaeological Discoveries in Samara Oblast. Samara: Samara Scientific Center (RAS), 2019. P. 15. (In Russ.)
Ryndina N. V. Copper finds of Khvalynsk I burial ground: results of technological research. In: Khvalynsk Copper Age Cemeteries and Khvalynsk Copper Age Cultures. Results of Research. Samara: Povolzhye, 2010. Pp. 234-257. (In Russ.)

Somov A. V., Shalapinin A. A. The ratio of the Neolithic and Eneolithic complexes of the forest-steppe Volga region according to radiocarbon dating. Samara Journal of Science. 2019. Vol. 8. No. 2 (27). Pp. 229-239. (In Russ.)

Tsibin V. A., Shalapinin A. A. Exploration work near the village of Maksimovka, Bogatovsky District. In: 2017 Archaeological Discoveries in Samara Oblast. Samara: Samara Scientific Center (RAS), 2018. P. 16. (In Russ.)

Tsibin V. A., Shalapinin A. A. The Eneolithic burial of Maksimovka I soil burial ground from the Samara Trans-Volga region. Science Journal of Volgograd State University. History. Area Studies. International Relations. 2019. Vol. 24. No. 3. Pp. 6-16. (In Russ.)

Vasilyev I. B. Khvalynsk Eneolithic culture of the Volga-Ural steppe and forest-steppe (some results of the study). In: Archaeological Issues of the Volga Region. Vol. 3. Samara: Samara Scientific Center (RAS), 2003. Pp. 61-99. (In Russ.)

Vasilyev I. B., Ovchinnikova N. V. Eneolithic. In: History of the Samara Volga Region from Ancient Times to the Present Day. Stone Age. Samara: Samara Scientific Center (RAS), 2000. Pp. 216-277. (In Russ.)

Vasilyeva I. N. Burials of nomads in the territory of the Kuibyshev Volga region. In: Ancient History of the Volga Region. Kuibyshev: Kuibyshev State Pedagogical Institute, 1979. Pp. 202-240. (In Russ.)

Vasilyeva I. N. The Golden Horde period in the history of the Samara Volga region. In: History of the Samara Volga Region from Ancient Times to the Present Day. Early Iron Age and Middle Ages. Samara: Samara Scientific Center (RAS), 2000. Pp. 293-346. (In Russ.) 


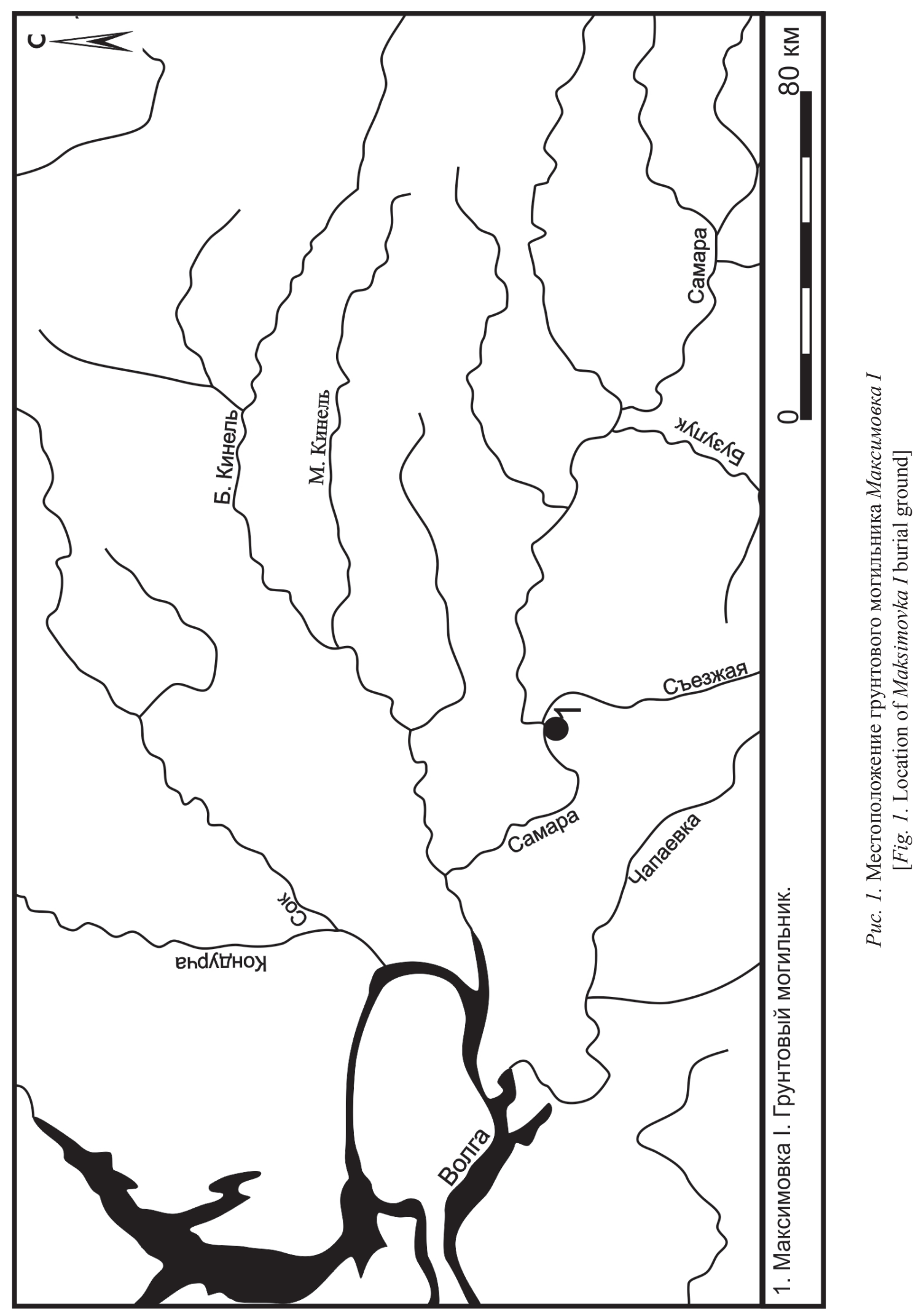




\section{Северная стенка}
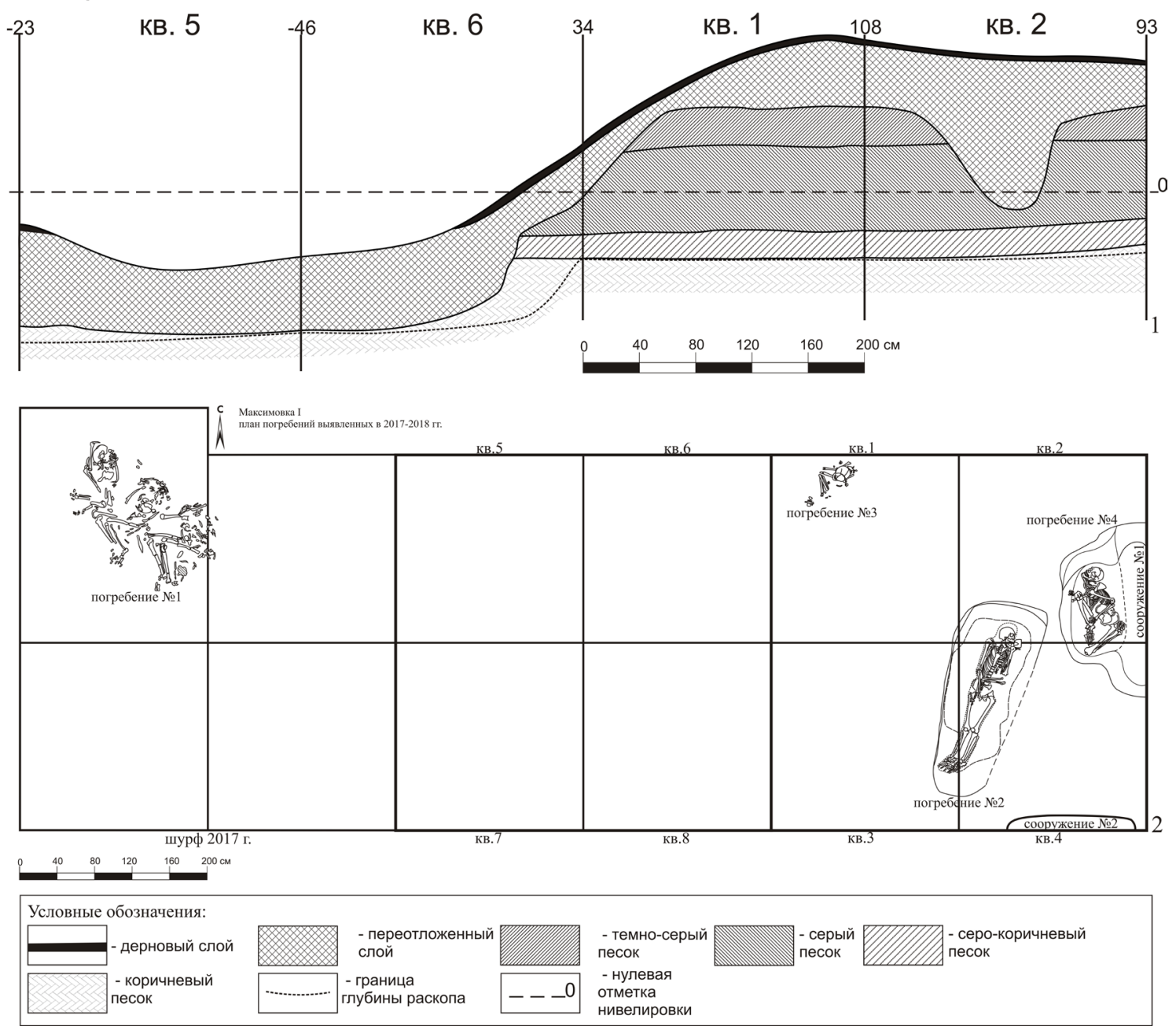

Puc. 2. Северная стенка раскопа (1), планиграфия могильника Максимовка I (2)

[Fig. 2. Northern wall of the excavation site (1), planigraphy of Maksimovka I burial ground (2)] 


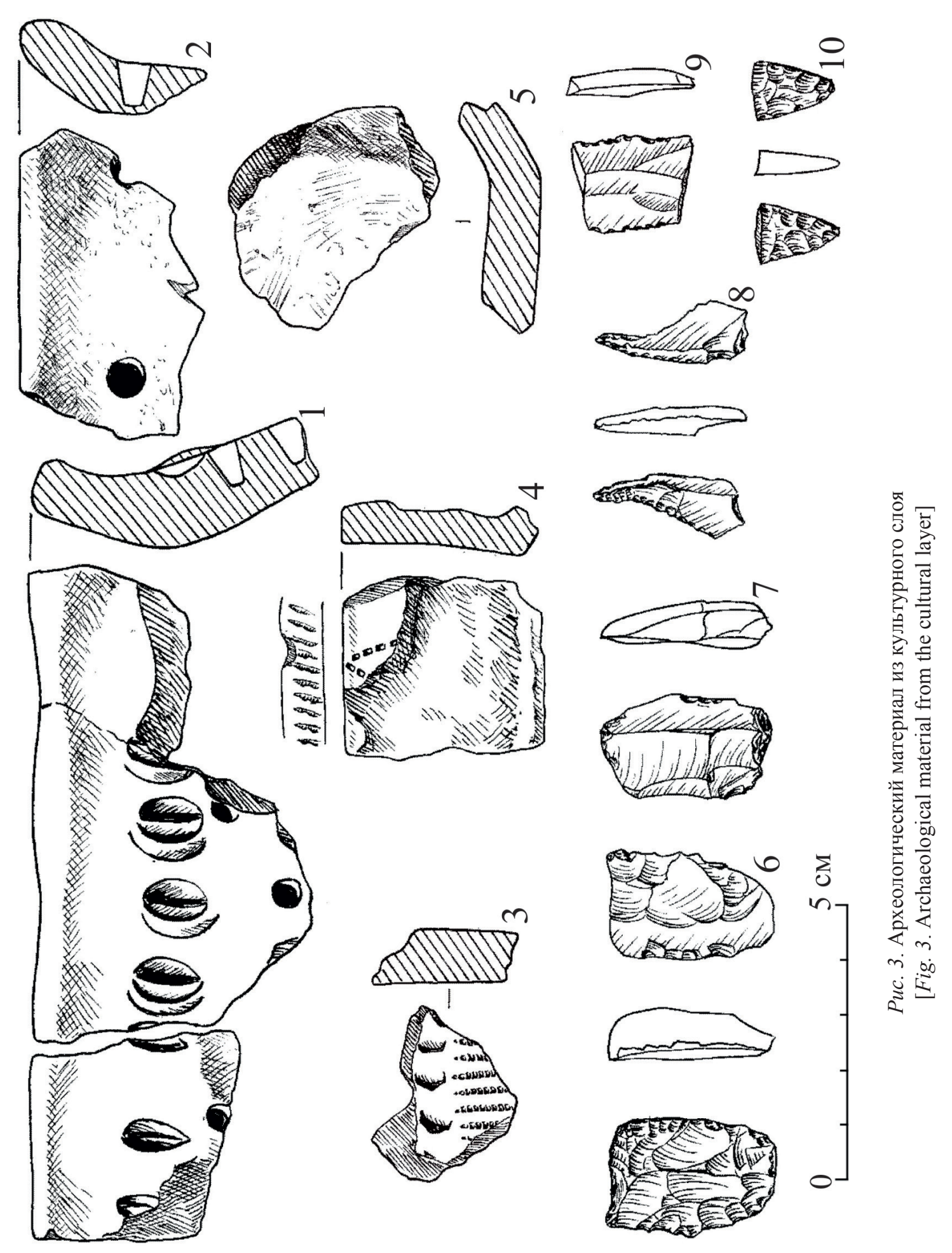




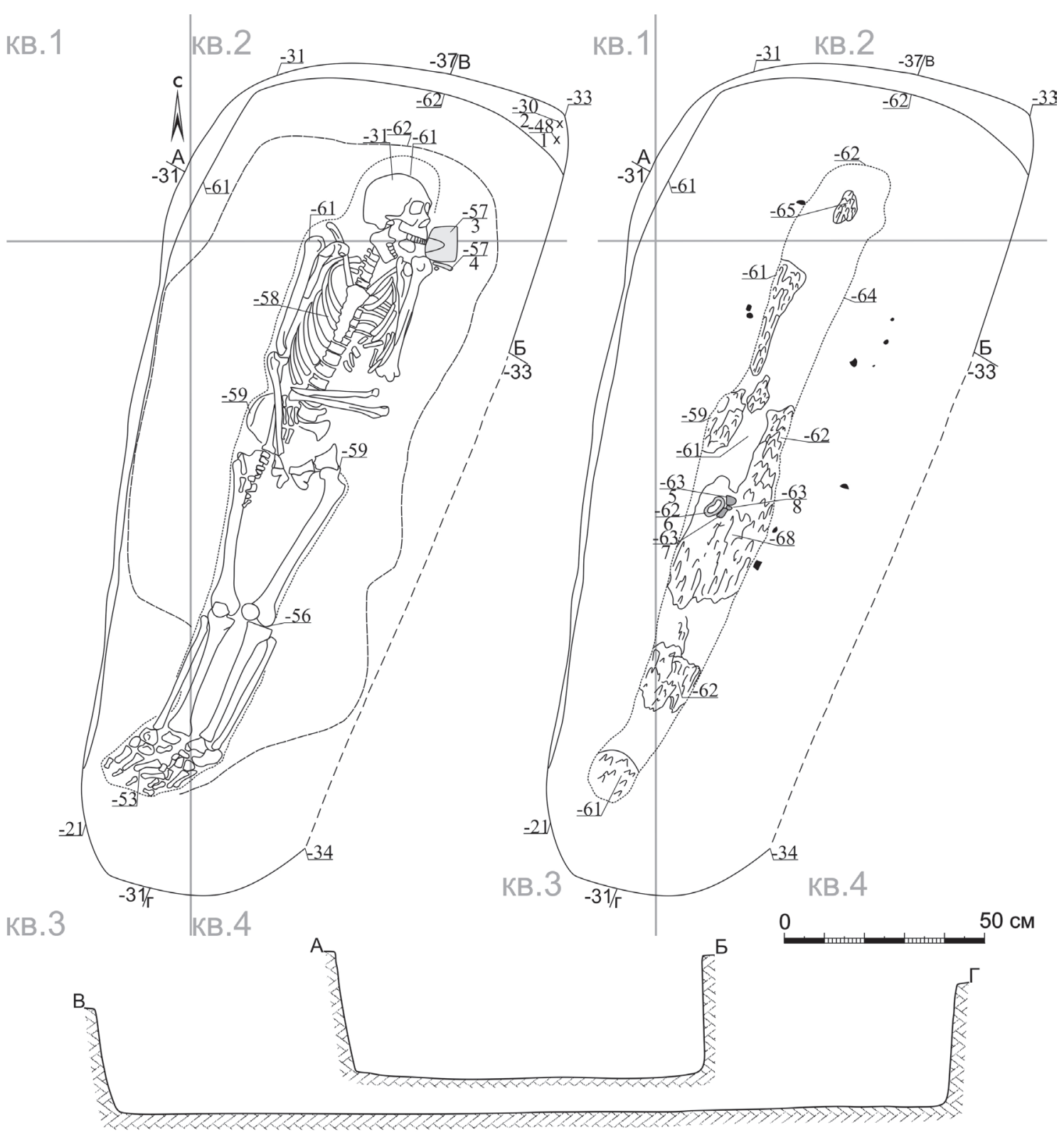

\begin{tabular}{|ll|}
\hline Условные обозначения & Археологический материал: \\
$\mathbf{X}$ металлический предмет & 1 - стержневидный железный предмет \\
$\square$ предмет из камня & 2 - составные железные удила \\
\hline уголек & 3 - фрагмент верхней части колла \\
\hline кора с сохранившейся структурой & 4 - стержневидный железный предмет \\
$\square$ кора & 5 - точильный камень \\
враница слоя серого песка с & 6 - кресало из железа \\
вкраплениям мелких угольков & 7 - кресальный камень \\
реконструируемая граница & 8 - кресальный камень \\
могильной ямы & \\
\hline коричневый песок (материк) & \\
\hline
\end{tabular}

Puc. 4. Погребение № 2

[Fig. 4. Burial No. 2] 


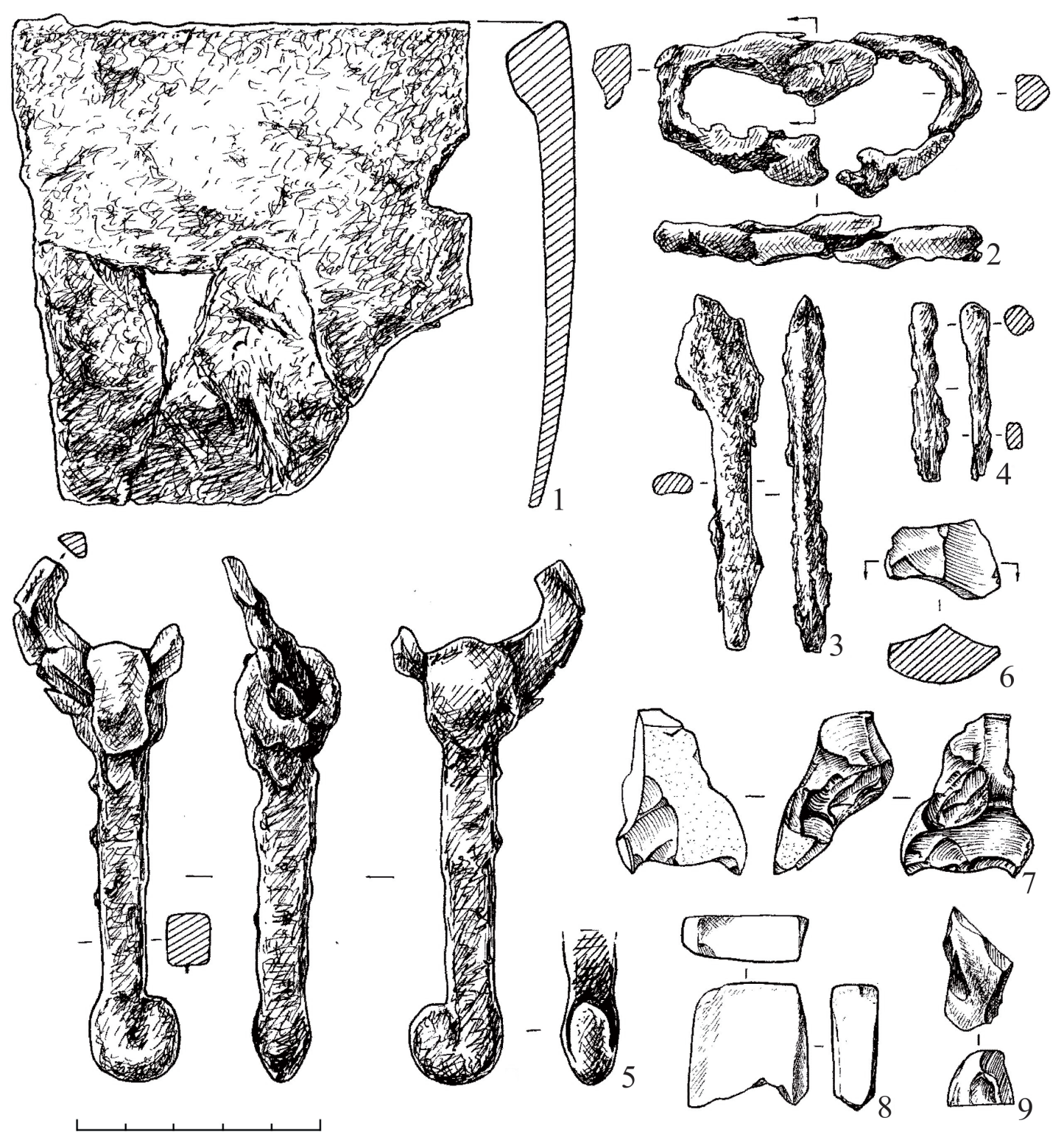

Puc. 5. Инвентарь из погребения № 2

[Fig. 5. Inventory from burial No. 2] 

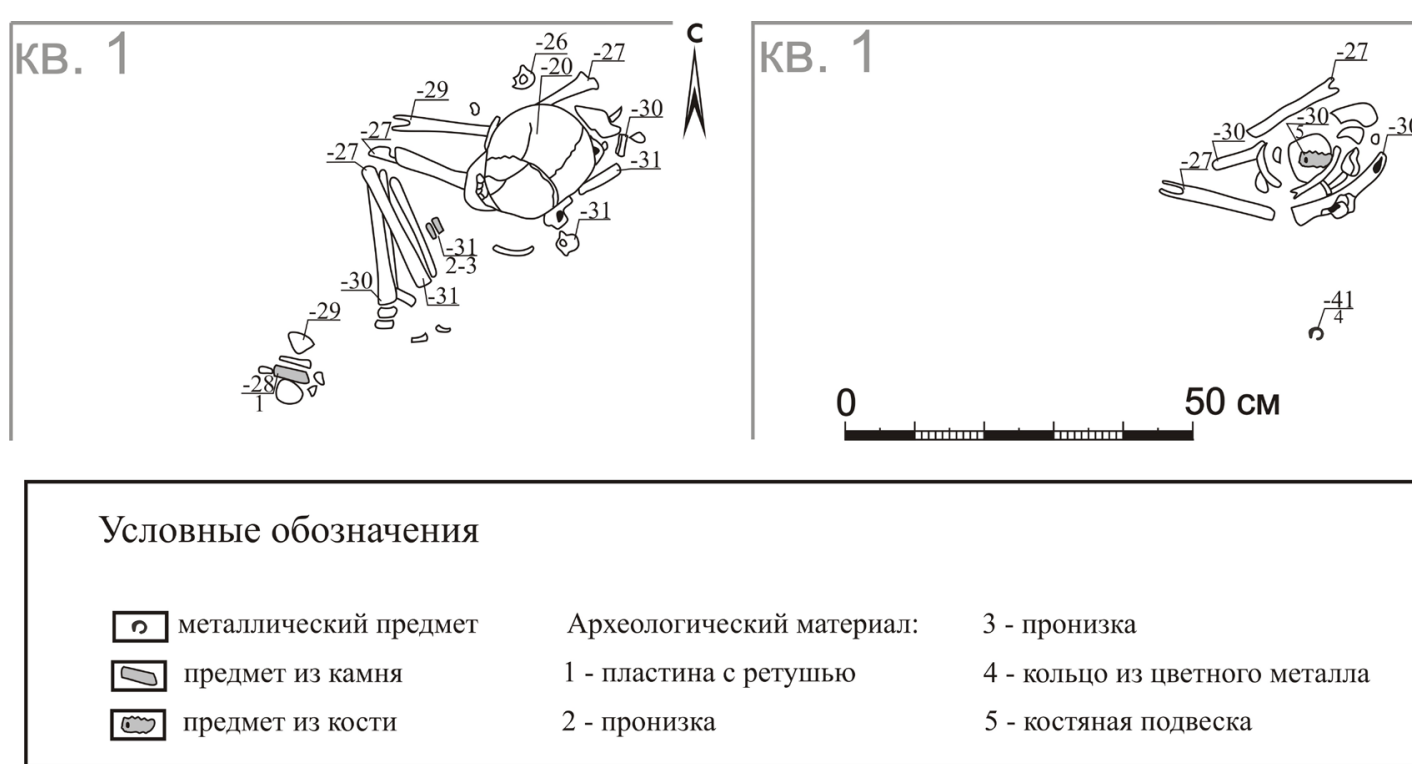

Рис. 6. Погребение № 3

[Fig. 6. Burial No. 3]
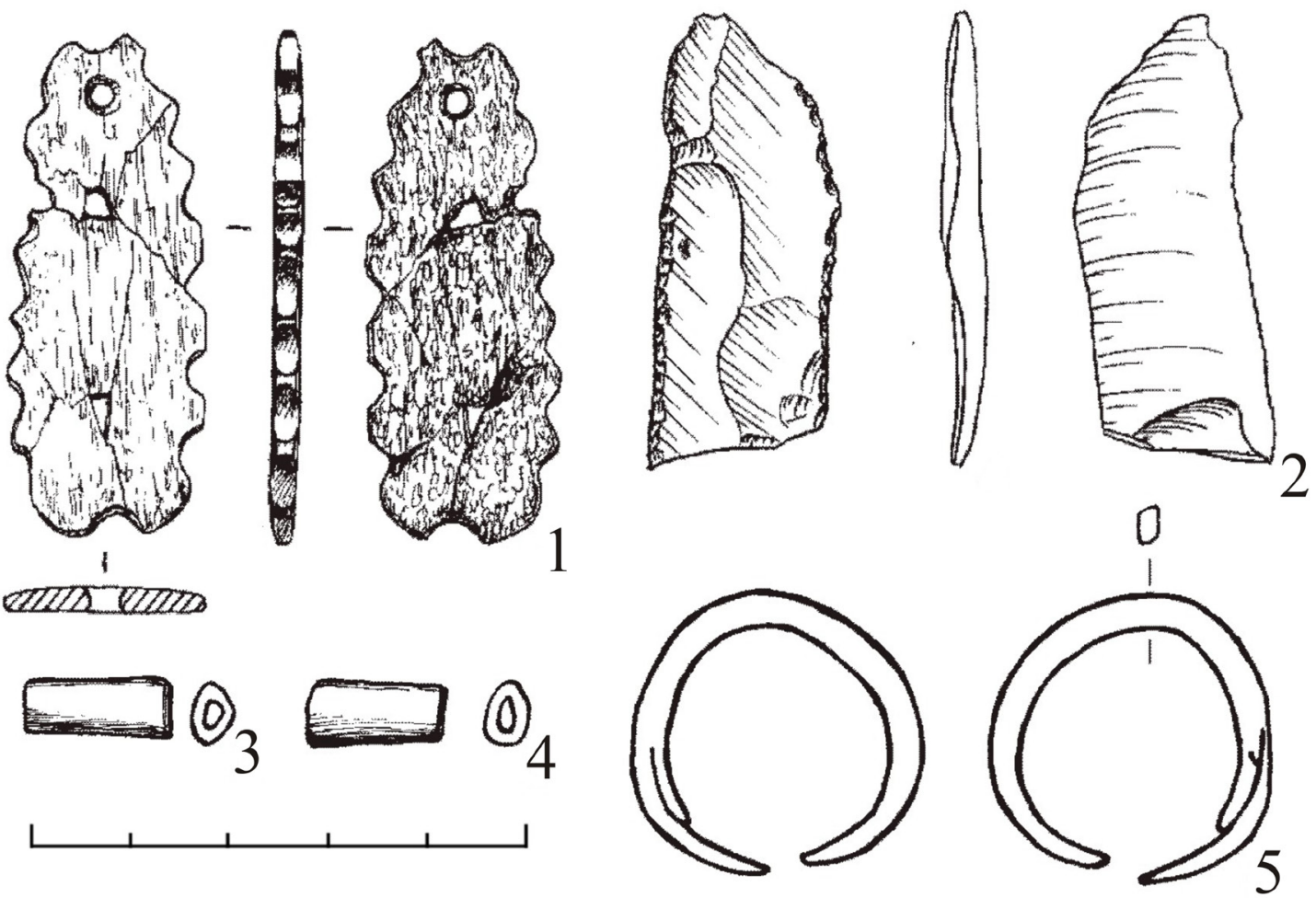

Puc. 7. Инвентарь из погребения № 3

[Fig. 7. Inventory from burial No. 3] 


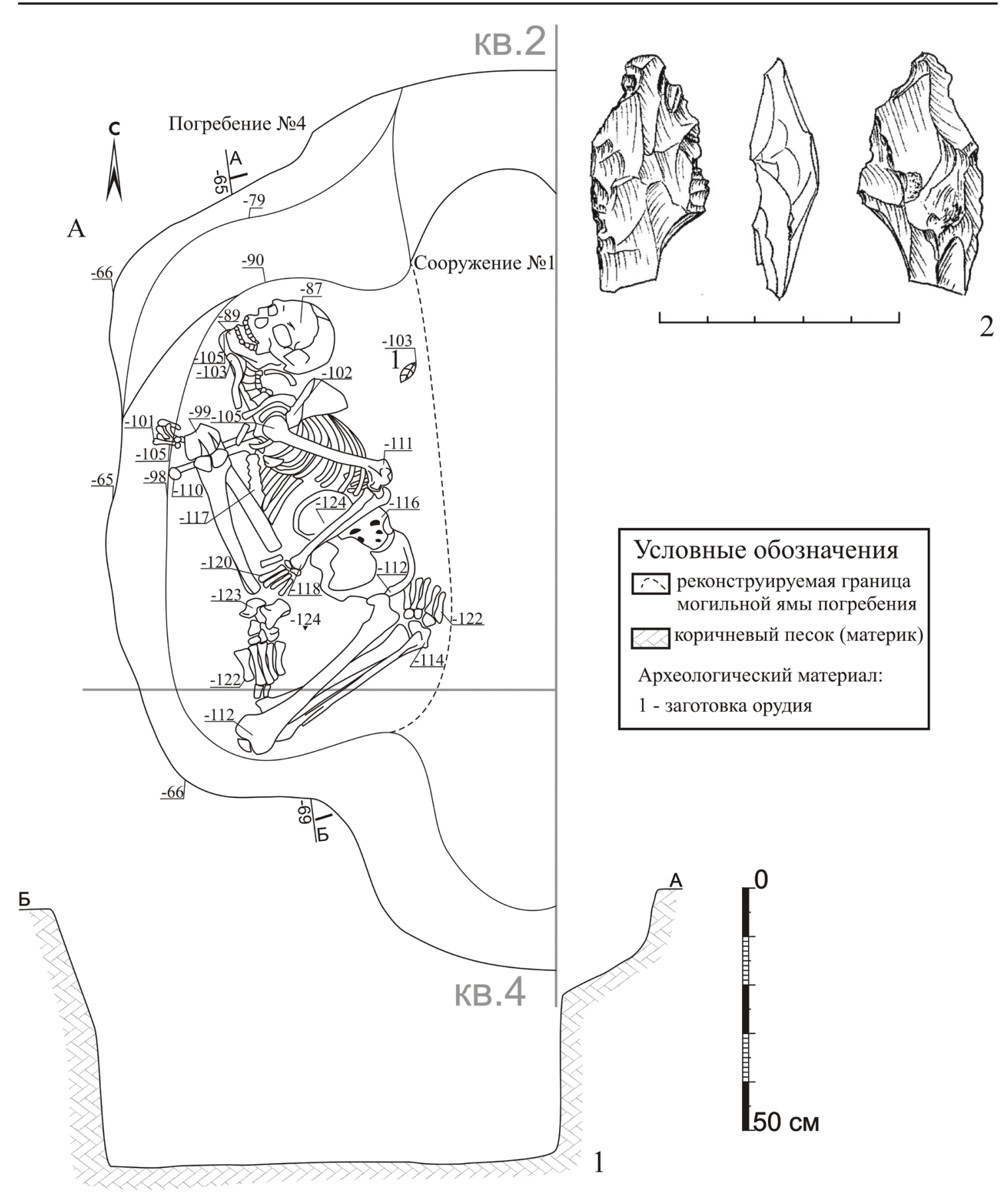

Puc. 8. Погребение № 4 (1) и сопутствующий инвентарь (2)

[Fig. 8. Burial No. 4 (1) and related inventory (2)] 